ISSN: 0212-0267

DOI: http://dx.doi.org/ro.I420I/hedu20I837383403

\title{
CREANDO PODER: LA EVOLUCIÓN DE LA AUTORIDAD DOCENTE EN ESPAÑA
}

\section{Creating power: The evolution of teacher authority in Spain}

\author{
Luján Lázaro Herrero \\ Universidad de Salamanca \\ Correo-e: lujan@usal.es \\ Eva García Redondo \\ Universidad de Salamanca \\ Correo-e: evagr@usal.es
}

Recepción: 22 de noviembre de 2017. Envío a informantes: 29 de enero de 2018 Aceptación definitiva: 22 de febrero de 2018

Resumen: Este trabajo pretende abordar el tema de la autoridad del profesorado ya que se ha convertido en un problema que desborda las barreras educativas, para convertirse en un asunto con entidad política. Para ello, realizamos un análisis de la evolución de la autoridad del docente a lo largo de los dos últimos siglos, contemplada a partir de los diferentes desarrollos legislativos. Como unidades de análisis, hemos tomado las leyes educativas que arrancan en el año 1857, con la Ley Moyano, hasta nuestros días, así como los desarrollos normativos surgidos al respecto a nivel autonómico.

El estudio de la normativa, desde una perspectiva histórica, nos va a permitir no solo constatar el papel que en cada momento social se le ha dado al docente, y cómo se ha recogido este a través de las regulaciones, sino la evolución del concepto de autoridad y el valor otorgado en cada época.

Palabras Clave: política educativa; derechos civiles; autoridad del docente; España; violencia.

AвSTRACT: This paper aims to address the subject of teacher authority as it has become a problem that has gone beyond educational barriers, to become a political 
issue. To do so, we analysed the evolution of teacher authority over the last two centuries, considered from its different portrayals in the legislation. As units of analysis, we have taken the education laws starting in 1857 , with the Moyano Law, to this day, as well as the regulatory developments that have arisen in this regard at the regional level.

The study of the regulations from a historical perspective will allow us not only to verify the role that has been given to the teacher at each moment in this time span, and how this has been collected in the regulations, but also the evolution of the concept of authority and the value granted to it at each different moment.

KEY WORDS: educational politics; civil rights; teaching authority; Spain; violence.

\section{Introducción}

on múltiples las voces que, en los últimos tiempos, se han hecho eco de un problema social que acecha el espacio educativo más tradicionali. La falta de $\checkmark$ autoridad docente o, en otras palabras, la pérdida progresiva y el imparable de control de y en las aulas se han convertido en tópicos que trascienden la esfera profesional, en la que parece que, hasta el momento, se encontraban resguardados, convirtiéndose en circunstancias comunitarias, investigadoras y, al mismo tiempo, políticas. Partiendo de esta idea, nos adentramos en el análisis de la cuestión, soportando que se trata de un tema esencial para la comprensión del fenómeno educativo actual. En este sentido, no podemos pasar por alto la premisa de la que parte el estudio de María Rosa Espot ${ }^{2}$ quien refiere, nítidamente, qué es la autoridad docente y cómo se puede llegar a alcanzar. Para ella, el paso de una educación restringida y privilegiada, destinada solo a unos cuantos elegidos, a un modelo mucho más democrático e igualitario ha desencadenado una nueva y actual interpretación de lo que significa la autoridad del profesorado. Asimismo, algunas circunstancias de corte sociopolítico - tales como el Estado de Bienestar, la mejora en los transportes y comunicaciones, el incremento en la preparación profesional e intelectual de los más jóvenes (futuros adultos), etc.- han contribuido a su alcance.

Como sabemos, la organización autonómica de nuestro país, España, reconoce un amplio, aunque restringido, abanico de competencias sociales, entre las que se encuentran, en un lugar reseñado, las que tienen que ver con la cuestión educativa. Siendo así, observamos cómo los diferentes gobiernos regionales trabajan por adecuar las directrices estatales a la realidad particular de cada uno de sus territorios, siendo, en el caso que nos ocupa, la autoridad una de ellas. Como bien apunta

VAillant, Denise Elena: «La identidad docente. La importancia del profesorado», en ColÉN, María Teresa; Jarauta, Beatriz y Domènech, Joan (coords.): Tendencias de la formación permanente del profesorado, Barcelona, Universitat de Barcelona, 2oro, pp. 9-24. TAllone, Alicia Esther: «Las transformaciones de la autoridad, en busca de una nueva legitimidad», Revista de Educación, número extraordinario (20II), pp. II5-I35.

2 Esрот, M. ${ }^{a}$ Rosa: La autoridad del profesor: qué es la autoridad y cómo se adquiere, Madrid, Wolters Kluwer España, 2006. 
Diker, es de imperiosa necesidad ofrecer a cada espacio unas directrices que les permitan «repensar la educación, como la acción pedagógica y el compromiso existente en estos espacios para luchar contra formas autoritarias que impiden un pensar con autonomía»3. Este mismo planteamiento es por el que, en los últimos tiempos, se ha interesado Hué, quien adopta un interesante argumento de partida reconociendo que para definir autoridad hay que conseguir distinguirlo de lo que es poder; dicho en otras palabras, aboga por discernir entre auctoritas y potestas. Hoy por hoy se entiende que

la potestas, es el poder del profesorado, emana de su nombramiento y se expresa mayoritariamente a través de las notas, mientras que la auctoritas, la autoridad, la ascendencia sobre los alumnos se consigue a partir de la confianza que podamos darles y esta confianza nace de un conjunto de competencias emocionales, nos dice el método de pensamiento emocional y para ello, nos propone un conjunto de ejercicios que nos ayuden a desarrollarlas ${ }^{4}$.

Ya en la Roma clásica, la dualidad entre la mencionada auctoritas y la potestas era el tópico dominante en las conversaciones desarrolladas en los foros. La principal diferencia entre ambas concepciones «estriba en que el poder puede utilizar la coacción y la autoridad no. Esta actúa mediante el respeto o la admiración que despierta en otras personas»`. Es, por ello, por lo que podemos afirmar que el poder de los ancianos frente al de los jóvenes, o el de los instruidos frente a los rústicos, compartía espacio con el conferido legalmente a los sacerdotes o, posteriormente, a los emperadores. La convivencia entre estas y otras autoridades, aunque conflictiva en determinados momentos, respondía a una organización que mantenía el orden social y permitía la convivencia pacífica y de clases, situación que no ha transcendido a nuestros días, tal y como explicaremos en las siguientes páginas.

Algo similar acontece durante el Medievo, cuando la organización de castas o los resultados iniciales de la colonización de América ofrecen nuevas formas de entender y, sobre todo, de aceptar la autoridad como forma de ejercicio de poder, del poder más cruel y menos democrático posible.

Sin embargo, esta tónica general se ve alterada, tal y como nos recuerda Trilla ${ }^{6}$, cuando la construcción en España de la soberanía docente se ve determinada por otros de índole político-educativa, tales como la ampliación de la escolaridad obligatoria a mediados del xIX, el impulso al mercado de consumo, el cambio en el rol femenino o la tendencia hacia el Estado del Bienestar, pero, al mismo tiempo, por circunstancias sociales asentadas, principalmente, en la reconocida crisis de valores arrastrada desde finales del siglo $\mathrm{xx}^{7}$, cuando se produce el revolucionario Mayo del 68.

Diker, Gabriela: «Autoridad y transmisión: algunas notas teóricas para re-pensar la educación», Revista Educación y Humanismo, Io (I5) (2008), p. 58.

4 HuÉ, Carlos: «Bienestar docente y pensamiento emocional», Revista Fuentes, I2 (2012), p. 62. Marina, José Antonio: La recuperación de la autoridad, Barcelona, Versátil, 2009, p. 22.

6 Trilla, Jaume: «Sobre la autoridad supuestamente perdida del profesorado», Cuadernos de Pedagogía, 396 (2009), pp. 22-26.

Bolívar, Antonio: «Efectos de la globalización en las vidas profesionales del profesorado», Revista de la Asociación de Inspectores de Educación de España, II (2009), pp. I-I8. 
La lucha por la libertad, como oposición a la autoridad impuesta, consigue alcanzar muchos defensores, superando la esfera política y centrándose en la revolución social e intelectual. Entonces la autoridad es, como nos recuerda Durán, una cuestión cada vez más discutida en nuestras sociedades, porque si, por una parte, se reclama su presencia, por otra, su misma invocación despierta recelo, en un mundo como el moderno que se ha construido de espaldas a este concepto $^{8}$. Es, a partir de ese momento, cuando la escuela pierde su autoridad institucional, lo que algún autor denomina "efecto de institución»", de la que los docentes eran herederos, siendo necesario demostrar esfuerzo y valía individual, moral y profesional, lo que redunda en una autoridad personal o individual ${ }^{10}$. Si la institución entra en crisis, si pierde prestigio, si deja de ser reconocida por la sociedad porque «tanto la escuela como la familia han dejado de funcionar como el soporte que garantizaba la legitimidad de los maestros»" la autoridad que Marina ${ }^{12}$ define como «recibida» se esfuma. En ese momento, hablaríamos de la incursión de la autoridad «merecida», aquella que no se recibe de nadie y que implica un reconocimiento por méritos propios, un poder legítimo ganado con esfuerzo. A todo ello se suma la confusión de normas, representada por una falta de claridad en las mismas, y la dificultad manifiesta de los jóvenes por identificarse con el mundo adulto, mostrando inconvenientes para reconocer y respetar el modelo de autoridad institucional y asumir responsabilidades.

Hecha esta categorización debemos apuntar que, mientras que la institucional y la recibida aparecen en la legislación que analizaremos correspondiéndose con la idea de auctoritas y potestas, respectivamente, la última está aún en periodo de expansión por ser la que se refiere más al valor añadido del propio poder institucional. En términos generales y anticipándonos a lo que veremos a continuación con el análisis de las distintas regulaciones, podemos considerar, por un lado, que la tendencia conservadora defiende la autoridad institucional y percibida frente a la personal, propia del progresismo y, por otro, que ninguna ley otorga autoridad al profesor y sí potestadi3.

Este planteamiento de Marina está en clara sintonía con el que ya ofreciera Erich Fromm ${ }^{14}$ a finales del siglo xx. Para el mencionado autor existen tres modalidades de autoridad sociopolítica que «si bien en un principio no fueron

8 Durán, José Francisco: «La crisis de autoridad en el mundo educativo. Una interpretación sociológica. Nómadas», Revista Crítica de Ciencias Sociales y Jurídicas, 28 (2010), 4, p. 172.

9 Tenti, Emilio: «Viejas y nuevas formas de autoridad docente», Revista Todavía, 7 (20Io), p. I.

to Arendt, Hannah: The human condition, Chicago, University of Chicago Press, 1958.

"Tenti, Emilio: «Viejas y nuevas formas de autoridad docente», Revista Todavía, 7 (20Io), p. I.

${ }_{12}$ Marina, José Antonio: La recuperación de la autoridad, Barcelona, Versátil, 2009.

${ }_{13}$ Espot, María Rosa y Nubiola, Jaume: «La autoridad del profesor en distintos entornos escolares: coeducativo y diferenciado", en Vidal, Enric y CAmps, Jaume (eds.): El tratamiento del género en la escuela, actas del I Congreso Internacional sobre Educación diferenciadas, Barcelona, European Association Single-Sex Education, 2007, pp. 323-340.

${ }^{14}$ Fromm, Erich: «Prólogo», en NeIll, Alexander: Sumerbill, México, Fondo de Cultura Económica, 2005. 
CREANDO PODER: LA EVOLUCIÓN DE LA AUTORIDAD DOCENTE EN ESPAÑA LUJÁN LÁZARO HERRERO Y EVA GARCÍA REDONDO

concebidas específicamente dentro de los ambientes educativos, tienen una total transferencia hacia ellos» ${ }^{15}$.

Primeramente, nos encontramos con la autoridad racional que destaca por permitir el crecimiento en libertad del educando y por garantizar su desarrollo pleno. En este caso, la autoridad se «impone» por actos probados, es decir, por las competencias de que cada educador dispone y aplica en relación a su ámbito laboral. El poder, el empecinamiento, la imposición quedan apartados en un modelo de autoridad mucho más sano, coherente y justo. Dicho en otras palabras, este modelo de autoridad destaca por ofrecer al alumno motivos objetivos para admirar al docente que son, a su vez, analizados, estudiados y reconsiderados para incrementar la mejora de la práctica educativa.

Lejos de este modelo se encuentran otras dos formas de autoridad que Fromm ha denominado «anónima» y «evidente» y que dan señas de un modelo pedagógico venenoso ${ }^{16}$ puesto que ambas incurren en un claro y amplio sentido opresor, de sumisión, de imposición, lo que supone una clara delimitación de las libertades sociales. La figura docente es la que determina qué es lo bueno y lo malo, sin entrar en posibilidad de debate o intercambio; sin embargo, cada una de ellas tiene sus armas particulares. Mientras que la anónima se permite la seducción y la persuasión para alcanzar sus fines proponiendo un espacio mucho más calmado de intervención educativa, la evidente recurre al castigo físico, las vejaciones, las amenazas y la ridiculización generando un clima mucho más tenso y peligroso.

En la actualidad la autoridad del profesorado queda explicitada gracias al trabajo que desde muchas de las comunidades autónomas se ha llevado, resultado, a la sazón, de la insistente reclamación del colectivo de un reconocimiento, respeto y confianza escasamente reflejado en las políticas educativas hasta el momento ${ }^{17}$. Con toda seguridad, reglamentar esta potestad del profesorado, explicitando lo que, hasta hace tan solo unos años, era una cuestión implícita se ha convertido en el germen del concepto y desarrollo de la idea de autoridad actual. En este sentido, la pérdida de poder del magisterio con la que se define a nuestro sistema educativo es, sin duda, el detonante de una situación mucho más trágica. Algunos autores, entre los que destacamos a Díaz, nos recuerdan que la mengua en la autoridad docente «es un problema íntimamente relacionado con la merma de la calidad del clima escolar ${ }^{\wedge}$.

Toda esta cuestión nos permite justificar el hecho de que, en los últimos tiempos, el tema de la autoridad del profesorado haya vuelto a ocupar las primeras líneas del debate educativo. Desde que la Constitución española, en su artículo

is Barba, José Juan: «Redefiniendo la autoridad en el aula. Posibilidades para una educación democrática», Retos. Nuevas Tendencias en Educación Física, Deporte y Recreación, I5 (2009), p. 4I.

${ }_{16}$ Miller, Alice: Por tu propio bien, Barcelona, Tusquets, I998.

${ }_{17}$ TALlone, Alicia Esther: «Las transformaciones de la autoridad, en busca de una nueva legitimidad», Revista de Educación, número extraordinario (20II), pp. II5-I35.

I8 DíAz, José Manuel: «Clima escolar, mediación y autoridad docente: el caso de España», Temas de Educación, 22, 2 (2016), p. 306. 
27, consagrara el derecho a la educación como un aspecto fundamental, la autoridad del profesor, tanto en el plano académico como en el de la disciplina, se ha contemplado como un aspecto elemental para avalar el disfrute individual de tal derecho. Así pues, la garantía del derecho particular a la educación, la mejora de la convivencia en los centros educativos y el aumento de la calidad de la enseñanza pasan por el refuerzo de la autoridad del profesorado, además de por otras circunstancias tales como la mejora en la formación del profesorado en convivencia $^{19}$. Esta garantía se hace, asimismo, extensiva a la autoridad de los equipos directivos en el desarrollo de su función y, en particular, del director, tal y como veremos que, en la actualidad, reconoce nuestra ley educativa.

Asumimos que, a día de hoy, el paso de la autoridad moral, más clásica y que defiende que el respeto debe ceñirse a una cuestión intelectual y profesional, a una pública, decretada por ley, ha provocado debates necesarios, ciertamente reseñables. Sin embargo, este planteamiento que ahora ofrecen estos autores como original y controvertido no es nuevo ni parece estar superado.

\section{Evolución de la autoridad docente en el marco legislativo español: pasado, presente y futuro}

Después de este repaso teórico por los conceptos e ideas más reseñables de la autoridad, pasamos a presentar algunos de los hitos legales que, gracias a su análisis histórico-educativo, clarificarán nuestro estudio.

Como anticipo, indicar que partimos de la idea de que son muchos y variados los factores que influyen en el desarrollo histórico del rol docente en nuestro país y que, por una cuestión operativa, hemos decidido estudiar a través de las diversas y sucesivas propuestas político-educativas que, a lo largo del pasado siglo y hasta la actualidad, han tenido lugar en España. Entendemos, por tanto, que estas, pese a no ser exclusivas, afectan inexorablemente a la progresión y avance educativo en relación a la autoridad.

\section{I. La centenaria Ley de I857}

El reconocimiento que la historia de la educación ha rendido siempre a la Ley de Instrucción Pública es más que merecido. Adelantada a su tiempo, esta norma supo contentar a los distintos partidos que, aun alcanzando el poder desde posiciones ideológicas bien distintas, tuvieron el mérito de optar por su mantenimiento, si bien con algunas regulaciones adyacentes que distinguían el poder político de cada grupo. Sin ánimo de hacer un amplio estudio de esta

19 Penalva, Antonia; Hernández, M. a Ángeles y Guerrero, Catalina: «Percepción de los expertos de la necesidad de formación del profesorado en convivencia», Revista Fuentes, I5 (2014), pp. 28I-304. 
ley puesto que ya han sido muchos y muy buenos los publicados ${ }^{20}$, creemos interesante remarcar para el tema que nos ocupa que a ella le debemos la organización escolar graduada en tres periodos y el reconocimiento del sistema dual de enseñanza -público-privado- ${ }^{21}$. En este nuevo marco de acción las figuras de autoridad pedagógica, como no podría ser menos, son muchas y variadas. La competencia educativa es compartida por autoridades del clero, militares, civiles, académicas y administrativas, reconociendo que la autoridad «ideal» (institucional) es aquella que alberga tras de sí una combinación entre lo académico y lo eclesiástico o administrativo (maestros además de párrocos, por ejemplo) tal y como se manifiesta en el propio articulado de la Ley: «El ejercicio del profesorado es compatible con el de cualquier profesión honrosa que no perjudique el cumplido desempeño de la enseñanza e incompatible con todo otro empleo o destino público» ${ }^{22}$. Además, reconocemos el establecimiento, por primera vez y de manera explícita, de distintos rangos profesionales que ubican a los maestros en el más bajo escalafón, seguidos de los profesores de enseñanzas medias, para culminar su cúspide con los inspectores y catedráticos tanto de instituto y enseñanza profesional como universitaria. Observamos, por tanto, cómo queda establecida una autoridad institucional, en el sentido anteriormente descrito de autoridad impuesta no objetiva.

Así mismo, no queremos dejar de destacar el trato diferenciado y desigual que reciben las maestras respecto a sus colegas varones en la ley decimonónica ${ }^{23}$. Aunque es verdad que esta circunstancia, tal y como nos reporta su lectura, se debe exclusivamente a retribuciones - «las Maestras tendrán de dotación respectivamente una tercera parte menos de lo señalado a los Maestros en la escala del art. I9I» ${ }^{24}$, entendemos que esta afecta a esa autoridad institucional y, lo que consideramos aún más grave, a la percibida. Con un mismo número de horas y clases a su cargo y similares competencias y obligaciones pedagógicas, «al proponer la creación de Escuelas Normales femeninas (art. II4)» ${ }^{25}$, las profesoras disponen de una peor percepción social en lo que respecta a su trabajo, posición y consideración social como autoridad. Esta clara situación de discriminación de género tiene como resultado un valor y mando social inferior al de los maestros.

20 Vega, Leoncio: Moderantismo y educación en España. Estudios en torno a la Ley Moyano, Zamora, Instituto de Estudios Zamoranos Florián Ocampo, 1995. Montero, Antonio: «Una ley centenaria. La Ley de Instrucción Pública (Ley Moyano, I857)», Cabás, I (2009), pp. I-Io.

${ }_{21}$ Álvarez, Antonio: «Los precedentes de la Ley Moyano», Revista de Educación, 240 (1975), pp. 5-I3.

${ }_{22}$ Ley de Instrucción Pública, 9 de septiembre de I857, Boletín Oficial del Ministerio de Fomento, art. 174 .

${ }^{23}$ SCAndon, Geraldine: «La mujer y la instrucción pública: de la Ley Moyano a la II.a República», Historia de la Educación. Revista Interuniversitaria, 6 (1987), pp. 193-207.

${ }_{24}$ Ley de Instrucción Pública, 9 de septiembre de 1857 , Boletín Oficial del Ministerio de Fomento, art. 194.

${ }_{25}$ SCANLON, Geraldine: «La mujer y la instrucción pública: de la Ley Moyano a la II. ${ }^{a}$ República», Historia de la Educación. Revista Interuniversitaria, 6 (1987), p. 194. 


\subsection{La propuesta de Villar Palasi frente al problema de la autoridad}

Tras más de ioo años de mantenimiento legal, la Ley de 1970 se encarga de reformular pedagógicamente el sentido de la educación. A partir de entonces la responsabilidad de dar oportunidad educativa al grueso de la población corre a cargo del Estado. Aunque en las décadas previas «el maestro encarna el orden disciplinario y es venerado, prestigiado y reconocido como autoridad ${ }^{26}$, los años 60 traen consigo una pérdida de valores que resiente la autoridad institucional del profesorado.

Próximo ya el fin del franquismo, el régimen es mucho más proclive al establecimiento de nuevas formas de entender la educación reglada que llegan desde contextos internacionales próximos y, lo que es aún más significativo para nuestro estudio, nuevas formas de comprender la autoridad. Considerando, siempre, que los principios de modernización pedagógica no atentan contra la integridad y esencia del gobierno, la nueva ley establece un articulado en el que se pone de manifiesto una expresión más avanzada de la autoridad docente. En este sentido, creemos interesante destacar el significado que tiene la ampliación de la escolaridad obligatoria. Aunque con ensayos a mediados de los 6o, el incremento hasta los I4 años asumido por esta ley trae consigo una reafirmación de la acción pedagógica del maestro, lo que supone un lógico aumento en el reconocimiento de la autoridad personal o, lo que es lo mismo, la autoridad del saber ${ }^{27}$. Esto implica una dignificación tanto de su estatus social (percibido), como del cultural y económico. La regulación de un sistema más avanzado y objetivo, tanto de oposiciones como de formación universitaria de índole pedagógica, permite la percepción de las autoridades educativas como ciertamente competentes, pero, a la vez, subordinadas al éxito de la obra, al ensayo y a la colaboración. La «llamada democracia orgánica, en la que las decisiones siempre quedaban reservadas a la autoridad delegada y en ningún caso elegida ${ }^{28}$ sigue estando presente.

Es, por ello, por lo que divisamos una apertura tímida hacia la autoridad personal, explicitada en esta norma a través de la definición del magisterio como colectivo con «relevantes cualidades humanas, pedagógicas y profesionales»"29, que no olvida la institucional en tanto que son los venidos a ocupar «en la sociedad española el destacado nivel que por su función les corresponde» $3^{30}$. Esta

26 Varela, Julia y Álvarez-Uría, Fernando: Arqueología de la escuela, Madrid, La Piqueta, I991, p. 36.

27 Espot, María Rosa y Nubiola, Jaume: «La autoridad del profesor en distintos entornos escolares: coeducativo y diferenciado», en VIDAL, Enric y CAmps, Jaume (eds.): El tratamiento del género en la escuela, actas del I congreso Internacional sobre Educación diferenciada, Barcelona, European Association Single-Sex Education, 2007, pp. 323-340.

${ }_{28}$ Mones, Jordi: «La Ley General de Educación de 1970. La Administración Educativa», Revista de Educación, número extraordinario (2012), p. 178.

29 Ley I4/1970 General de Educación y Financiamiento de la Reforma Educativa, Boletín Oficial del Estado, 187, 6 de agosto de 1970, p. I2527.

30 Ibid. 
CREANDO PODER: LA EVOLUCIÓN DE LA AUTORIDAD DOCENTE EN ESPAÑA LUJÁN LÁZARO HERRERO Y EVA GARCÍA REDONDO

última idea reafirma, en cierto modo, lo que Tallone defiende: «la escuela perdió su autoridad institucional, [...] por la que eran respetados con independencia de sus características concretas [...]. Por eso el esfuerzo personal era casi innecesario ${ }^{31}$.

\subsection{El papel de la Ley Orgánica $5 / 1980$, de la Jefatura del Estado, de Ig de junio, por la que se regula el Estatuto de Centros Escolares}

La LOECE, como habitualmente se conoce a esta ley, destaca por un incipiente carácter democrático, no en vano es la primera norma de este tipo que se publica tras el cambio de régimen. Tras casi 40 años de dictadura totalitaria, y aun con la apertura resultante de la publicación de la LGE, son algunas las cuestiones que, de manera novedosa, este texto aporta al estudio de la autoridad docente en España. Quizás la más destacable sea la que se refiere a que, por primera vez, el profesor es reconocido como empleado público. Aunque lejos está todavía la consideración actual como autoridad pública, esta regulación obliga al docente a respetar la Constitución, cumplir con la ley educativa vigente y garantizar la buena aplicación de los documentos institucionales que forman parte de la vida diaria de los centros, especialmente lo dictado en el Reglamento de Régimen Interno y en el Ideario de Centro, en públicos y privados, respectivamente. Sin embargo, la autoridad individual, gran éxito alcanzado por la Ley del 70, permanece intacta e incluso se ve incrementada siendo más exigente con la formación del profesorado y con sus tareas de investigación y experimentación.

Asimismo, confirma la responsabilidad última del profesorado en lo que se refiere a la «formación integral de los alumnos, adecuada a su edad, que contribuya a educar su conciencia moral y cívica, en forma respetuosa con la libertad y dignidad personales de los mismos» ${ }^{2}$. Ello supone una amplia confianza en sus métodos, estrategias y capacidades lo que, en otras palabras, implica un reconocimiento a su figura en términos de autoridad educativa.

En tan solo una ocasión menciona de manera textual la autoridad para referirse, exclusivamente, al director de centros, depositando en su figura el mando y orden desde una perspectiva relativamente democrática. Son los propios docentes funcionarios del centro, sus colegas, los que deciden su nombramiento. Siendo así, observamos en este hecho un claro reflejo de autoridad merecida, si bien es verdad que la falta de total objetividad entre sus electores pudiera ocasionar ciertas dudas al respecto. Aun con todo, debemos considerar lo legislado en la LOECE como un claro y enérgico avance por alcanzar una autoridad mucho más real y democrática.

${ }^{31}$ TAllone, Alicia Esther: «Las trasformaciones de la autoridad docente, en busca de una nueva legitimidad», Revista de Educación, número extraordinario (20II), p. I32.

32 Ley Orgánica $5 / 1980$, de 19 de junio, por la que se regula el Estatuto de Centros docentes, Boletín Oficial del Estado, 154, 27 de junio de 1980, p. I4634. 


\subsection{La LODE y su interpretación del poder docente}

Tan solo 5 años más tarde, en 1985, el Gobierno socialista sanciona una nueva norma que, en este caso, destaca tanto por su mantenimiento en el tiempo como por su propuesta de transparencia en todos los procesos de decisión que tienen lugar en la escuela.

Sin duda, reseñable es el reconocimiento que, en forma de obligación, hace de los agentes educativos implicados en la acción pedagógica. Así, la participación de las autoridades docentes, educativas y familiares se combina con la del propio alumnado, hasta el momento ciertamente alejado de las cuestiones referentes a la vida escolar ${ }^{33}$. Se establece, así, un nuevo órgano que ejerce la autoridad pedagógica velando por la mejora de la calidad educativa.

Significamos, en este momento, la constitución de tres órganos de poder escolar. Por un lado, Consejo Escolar del Estado, encargado de la «participación de los sectores afectados en la programación general de la enseñanza y de asesoramiento respecto de los proyectos de ley o reglamentos que hayan de ser propuestos o dictados por el Gobierno» ${ }^{4}$, encabezado por un presidente elegido por la administración, hecho que le otorga una autoridad institucional, y conformado por un conjunto de personalidades de reconocido prestigio en el campo de la educación. He aquí la autoridad percibida. Por otro lado, los diversos consejos regionales de cada una de las comunidades autónomas constituidos por personas de distinta índole, pero con una característica común: pertenecer a un sector afectado. Finalmente, los de Centro que, como órgano colegiado y democrático en el que participan docentes, administración, padres y alumnos, reportan una autoridad recibida.

\subsection{La reformulación de la autoridad en la Ley de Ordenación General del Sistema Educativo}

Poco avanza, al menos textualmente, la LOGSE en el tema que analizamos, si bien es verdad que encontramos una forma diferente de entender el papel del docente en el medio escolar. Hasta el momento, el profesorado ha sido considerado como colectivo cuantitativo mientras que, desde ese momento, el colectivo es reconocido teniendo en cuenta que «las condiciones profesionales en las que ejerce su función el profesorado difieren, cualitativamente, de las entonces imperantes» ${ }^{35}$.

Esta nueva visión de los profesores que se recoge en la ley propone la adaptación tanto del currículo que imparten como de sus condiciones de práctica. Así, puesto que la realidad del alumnado, del país, de la sociedad, de la economía,

33 Espot, María Rosa: La autoridad del profesor. Qué es la autoridad y cómo se adquiere, Madrid, Wolters Kluwer Educación, 2006.

${ }_{34}$ Ley Orgánica 8/1985 reguladora del Derecho a la Educación, Boletín Oficial del Estado, I59, 4 de julio de 1985 , p. 2 IOI8.

35 Ley Orgánica I/1990, de 3 de octubre de I990, de Ordenación General del Sistema Educativo, Boletín Oficial del Estado, 238, 4 de octubre de 1990, pp. 28927-28942 (ref. en p. 28977). 
del profesorado ha cambiado, se hace imprescindible una nueva formulación del concepto de autoridad.

Comprobamos, en este sentido, como esta norma propone un salto cuantitativo, que inicia la prioridad de la autoridad reconocida. Así, su lectura y análisis nos permite observar y reconocer el necesario despliegue del docente como mecanismo básico en la tarea social, situándolo en lo más alto y transmitiendo esa idea al resto de la ciudadanía. El profesor ya no es solo un elemento más, sino que es un eje imprescindible y clave que, junto al discente, favorece el desarrollo de un proyecto común. Este solo se entiende con la participación de todos sus implicados, entre los cuales, el docente ejerce un liderazgo otorgado y una autoridad merecida gracias a la labor investigadora, el trabajo en equipo y la formación permanente, entendiendo que todo ello ayuda a la expansión de los resultados, a la visibilidad de su trabajo $\mathrm{y}$, en términos generales, a la mejora de la calidad docente y educativa.

\subsection{Ley Orgánica de Participación, Evaluación y Gobierno de los Centros Docentes. El privilegio legal de los inspectores}

Esta línea iniciada con la LODE y continuada con la LOGSE respecto a reconocimiento y participación es mantenida con la LOPEG de I995. Por primera vez se sanciona al docente como autoridad pública, protagonista que junto a la inspección mayores beneficios de poder alcanza. Centraremos nuestra atención en estos últimos, al ser los que de manera más firme y amplia gozan de ese «privilegio». Esta situación la debemos leer en términos de desigualdad entre agentes educativos profesionales dado que, pese a que todos son considerados autoridad, solo los inspectores gozan de un mayor campo de acción, de jure y de facto.

Esa dual percepción es la que genera un debate, en el que algunas de las propuestas e iniciativas sindicales que abogan por una equiparación de todos los agentes implicados en el proceso educador de la escuela se dejan oír proponiendo una vuelta a la autoridad institucional, en unos términos similares a los que describimos para la Ley de I857, pero con una lógica evolución adecuada a la problemática propia del cercano siglo xxI.

Pese a las diferencias entre ambos, la autoridad percibida según lo que la ley defiende y lo que se deriva de su propio trabajo está presente.

\subsection{El reconocimiento del profesor en el marco de la Ley Orgánica de Educación}

En atención a lo apuntado anteriormente, es la reformadora LOE (2006) la que pretende atender a los graves problemas de convivencia que se observan en los centros educativos al inicio de siglo y que derivan en la ya conocida como «crisis de autoridad $»^{36}$. En este sentido, destacan como soluciones inmediatas la clarificación

36 VInUesa, José Manuel: «La crisis de autoridad en la educación», Acontecimiento: Órgano de Expresión del Instituto Emmanuel Mounier, 58 (200I), pp. 47-51. 
de normas, la delimitación de márgenes de actuación pedagógica y la descripción de lo que debe ser la autoridad docente en lo que respecta a protección, asistencia jurídica y responsabilidad civil.

Como bien se encarga de apuntar el texto legal, el «necesario reconocimiento social de la función que los profesores desempeñan y de la tarea que desarrollan ${ }^{37}$ es condición sine qua non para mejorar la calidad de un sistema con resultados poco esperanzadores, tal y como nos informan los reiterados informes PISA. El «[...] compromiso decidido con los objetivos educativos planteados por la Unión Europea para los próximos años: mejorar la calidad y la eficacia de los sistemas de educación y formación, facilitar el acceso generalizado a estos sistemas y abrirlos al mundo laboral, a la investigación y a la sociedad en general $\aleph^{3^{8}}$, deriva en el establecimiento de un modelo de formación inicial del profesorado equiparado no solo al conjunto europeo, sino también al conjunto de titulaciones nacionales. Es así como la aplicación del mandato Bolonia a la Enseñanza Superior contribuye a la mejora de la percepción de la docencia de nuestro país, aún sin una aplicada ley estatal que equipare al profesorado con otras autoridades públicas, tales son, por ejemplo, los miembros de las Fuerzas y Cuerpos de Seguridad del Estado o los de la ya mencionada inspección educativa.

\section{La visibilidad del enseñante como autoridad: la LOMCE y sus regulaciones autonómicas}

En 2013 se publicaba, no sin polémica, nuestra actual ley de educación. En este caso, más que proponer un texto completamente novedoso, opta por reformar el articulado de la LOE, obviando algunos de sus principios y añadiendo otros tantos. El cariz conservador que recorre la misma se justifica aludiendo, por un lado, a estudios internacionales elaborados por el Banco Mundial y la OCDE, en los que la calidad de la educación española sale mal parada y, por otro, al necesario ejercicio de reflexión en torno a la transformación de las condiciones sociales, culturales y económicas que afectan a «una realidad que nos interpela, es decir, nos hace pensar, nos desafía»39.

Anteriormente hablábamos de los cambios acaecidos en las últimas décadas y de su repercusión en el conjunto de las instituciones educativas y en el papel del profesor. La mejora de la calidad educativa es un fin que subyace en la justificación de esta reforma legislativa y que arrastra directamente al profesorado como objetivo principal de esta mejora, donde «el prestigio de la profesión docente es

37 Ley Orgánica 2/2006, de 3 de mayo, de Educación, Boletín Oficial del Estado, 106, 4 de mayo de 2006, p. I716r.

${ }_{38}$ Espot, María Rosa: La autoridad del profesor. Qué es la autoridad y cómo se adquiere, Madrid, Wolters Kluwer Educación, 2006, p. II3.

39 Milovich, Mariana: "Construcción de la autoridad docente», en Maliandi, Ricardo (comp.): Actas de las III Jornadas Nacionales de Ética y I Jornadas Interdisciplinarias UCES: sobre la Autoridad: perspectivas interdisciplinarias y prácticas sociales, Buenos Aires, FUCEs, 20II, p. I47. 
señalado con frecuencia como un factor clave» $4^{\circ}$. A pesar de encontrarnos en un momento donde la Pedagogía parece que quiere buscar nuevos senderos en la enseñanza, romper con fórmulas que se consideran encorsetadas y dar más libertad al alumno en el proceso de enseñanza-aprendizaje, hay voces que apelan a la recuperación de la disciplina y la autoridad de los docentes en las aulas. Ese es el caso de la exasesora del Ministerio de Educación sueco Inger Enkvist. Abanderada de la llamada "cultura del esfuerzo», reclama mayor autoridad por parte del profesor en detrimento de la autonomía del alumno, ya que la libertad que se le otorga en la actualidad no es beneficiosa ${ }^{41}$ para la función educativa.

A lo largo de este camino, nos hemos topado con afirmaciones que valoran directamente la crisis del profesor ligada esta a las nuevas tareas que supuestamente se le encomiendan, que distan de su vocación, y a la asunción de responsabilidades que pertenecerían más a la esfera familiar que escolar. Y así lo manifiesta en su preámbulo la Ley de Autoridad del Profesor de la Comunidad de Madrid, a la vez que justifica la necesidad de adoptar medidas legales para reforzar la autoridad de maestros y profesores con el fin de garantizar el derecho individual a la educación, mejorar la convivencia en los centros educativos y aumentar la calidad de la enseñanza

El resultado ha sido un descenso de la valoración social de la función docente y una pérdida de autoridad de los profesores que se manifiesta no sólo en episodios graves, aunque afortunadamente aislados, de violencia escolar, sino también en una tendencia a la indisciplina en las aulas. Con cierta frecuencia el profesor pierde la mitad de su valioso tiempo en mantener el orden necesario para desarrollar su tarea docente, lo que perjudica al conjunto de los alumnos y deteriora la calidad de la enseñanza ${ }^{42}$.

En cualquier caso, la justificación que se realiza al respecto no parece estar del todo fundamentada con datos que muestren la percepción real de la sociedad española respecto al profesor. Así, el barómetro del CIS $^{43}$ publicado en febrero del mismo año en el que se aprueba la citada ley nos da información respecto a la valoración por parte de los ciudadanos de una serie de profesiones u oficios. Encabeza la lista como profesión más valorada la de Médico (8I,58 puntos) seguida de cinco oficios afines a la docencia y al trabajo de profesor: Profesor/a universitario/a (75,16), Profesor de Primaria (74,70), Maestro/a de Educación Infantil $(74,64)$, Profesor/a de Educación Secundaria $(73,67)$ y Profesor/a de Formación Profesional (73,92). Aun así, llama la atención el hecho de que ante la

$4^{\circ}$ Fundación Europea Sociedad y Educación: El prestigio de la profesión docente en España. Percepción y realidad, Informe, 20I2, p. I5. http://www.sociedadyeducacion.org/site/wp-content/uploads/Informe.pdf.

${ }_{41}$ Enkvist, Inger: La buena y la mala educación, Madrid, Encuentro, $201 \mathrm{I}$.

${ }_{42}$ Ley 2/20Io, de Is de junio, de Autoridad del Profesor, Boletín Oficial del Estado, 238, I de octubre de 2010 , p. I.

${ }^{43}$ CIs: Barómetro de febrero. Avance de resultados, Estudio número 2.978, 2017, en http://datos. cis.es/pdf/Es2978mar_A.pdf. 
pregunta; ¿qué profesiones de esa lista recomendarían a sus hijos o a un buen amigo/a?, Médico sigue siendo la más mencionada (46,I) y las del área docente quedan desplazadas a posiciones más inferiores, siendo la de Profesor/a de Universidad la mejor situada de todas ellas (II,7).

Deteniéndonos más directamente en la figura del docente, la Tabla i recoge las consideraciones de la ciudadanía respecto al prestigio social del oficio de profesor depositado a través de las diferentes figuras ligadas al mismo. Destacan los valores otorgados a la opción de «bastante» que suelen ir muy próximos a los concedidos para el caso de "poco" salvo en la figura de Maestro/a de Infantil que la segunda supera a la primera. Esto quiere decir que dos percepciones que son distantes entre sí están muy próximas en puntuación. Se desmarca de esta visión la otorgada al Profesor/a de Universidad que recibe un reconocimiento muy alto tanto en la opción de «mucho» como de «bastante», lo que confirma que se trata de una profesión que goza de gran prestigio en la sociedad española y que se diferencia del oficio ligado al magisterio.

Tabla I. Prestigio social de la profesión de profesor

\begin{tabular}{|l|c|c|c|c|c|c|}
\hline Una Profesión Que...Tiene Prestigio social & Mucho & Bastante & Poco & NADA & N/S & N/C \\
\hline Maestro/a de Educación Infantil & 4,6 & $4 \mathrm{I}, 7$ & 43,8 & 5,8 & 3,8 & 0,2 \\
\hline Profesor/a de Primaria & 5,3 & 43,6 & 42,3 & 4,8 & 3,7 & 0,2 \\
\hline Profesor/a de Educación Secundaria & 7,4 & 46,6 & $38, \mathrm{I}$ & 3,8 & 3,7 & 0,4 \\
\hline Profesor/a deformación Profesional & 7,3 & $4 \mathrm{I}, 8$ & 37,7 & 5,0 & 7,7 & 0,5 \\
\hline Profesor/a de Universidad & 37,8 & 47,6 & $\mathrm{IO}, \mathrm{I} 4$ & $\mathrm{I}, \mathrm{I}$ & 2,9 & 0,3 \\
\hline
\end{tabular}

Fuente: Elaboración propia a partir de los datos del cis (2013).

Pese a que sabemos que «el ejercicio docente de la autoridad supone comprender que en nuestra actualidad no existen "autoridades", en el sentido de personas que todo lo saben y que, por saberlo, no tienen derecho a equivocarse y, si lo hacen, constituye un descrédito reconocerlo» ${ }^{44}$, nuestra actual ley educativa reinstala la figura de autoridad desde una perspectiva ciertamente institucional. Equipo directivo y equipo docente son considerados autoridad pública de manera que

en los procedimientos de adopción de medidas correctoras, los hechos constatados por profesores, profesoras y miembros del Equipo Directivo de los centros docentes tendrán valor probatorio y disfrutarán de presunción de veracidad «iuris tantum»o salvo prueba en contrario, sin perjuicio de las pruebas que, en defensa de los respectivos derechos o intereses, puedan señalar o aportar los propios alumnos y alumnas ${ }^{45}$.

De cualquier forma, y a pesar de que no todos ven como vital la regulación de la consideración del profesor dentro y fuera de la institución escolar, la cuestión

44 Heler, Mario: Cuestiones ético-profesionales de la actividad docente: la cuestión de la autoridad, Lleida, Universidad de Lleida-ICE, 2000.

45 Ley Orgánica 8/2013, de 9 de diciembre, para la Mejora de la Calidad Educativa, Boletín Ofcial del Estado, 295, Io de diciembre de 2013, pp. 97858-9792I (ref. en p. 97903-97904). 
de la autoridad es una de las más controvertidas. Desde 2013, el tan anhelado respeto se concreta en la posibilidad de adoptar medidas correctoras contra los discentes cuando existan hechos constatados por parte de profesores, profesoras y miembros del equipo directivo.

En este sentido, conceder al docente la condición de autoridad pública significa dotarle de una mayor cobertura jurídica ante los posibles escenarios de falta de convivencia. Tales situaciones pasan a tener una gravedad penal al poder ser consideradas delito de atentado a la autoridad.

Este reconocimiento nacional no es más que el reflejo de las acciones locales publicadas con anterioridad por un amplio número de comunidades autónomas. Preocupadas por la situación del docente, varias regiones optaron por anticiparse a la norma estatal, ofreciendo otras que de manera específica aludiesen al reconocimiento del docente como autoridad pública. Aunque la veda fue abierta por Madrid y Valencia, ambas en 2oro, la sucesión no se hizo esperar. Tan solo un año más tarde se une La Rioja, a la que meses después se añaden Castilla-La Mancha y Aragón, no siendo hasta 20I3 cuando lo hacen Asturias y Murcia. La última en unirse en $20 \mathrm{O} 4 \mathrm{y}$, por tanto, con cierto retraso al ya estar reconocida en la norma estatal es Castilla y León, quedando actualmente en espera la norma de Extremadura, que desde hace unos años se encuentra "debatiendo» su anteproyecto y que, al cierre de este trabajo, no hemos podido constatar su aprobación.

Si tomamos como ejemplo la regulación llevada a cabo en la Comunidad de Madrid, que sirvió de base y abrió el camino a otras ordenaciones posteriores, podemos destacar que se trata de una normativa que responde a la necesidad de adoptar medidas encaminadas al reconocimiento de la figura del profesor, mejorar la calidad de la enseñanza y optimizar la convivencia en los centros educativos. Para ello, cada centro debe contar con sus propias normas de organización y de funcionamiento, articulando mecanismos de sanción en el caso de que estas sean quebrantadas. Es evidente el intento de refuerzo institucional del docente, aparentemente perdido, y la acentuación de un perfil profesional que se presenta como la pieza clave para la consecución de los objetivos tan deseados de éxito educativo.

Tal y como muestra la Tabla II, el resto de comunidades autónomas que han tomado medidas en este terreno siguen la estela marcada por el desarrollo legal articulado en la capital española. Estas regulaciones son, prácticamente, un calco entre sí. Todas ellas van encaminadas a restaurar y potenciar la figura del profesor, entendiendo que su prestigio profesional está en peligro y destacando la incipiente incursión de episodios de violencia escolar que, si bien no son numerosos en términos absolutos, sí son notorios y preocupantes.

En este sentido, se reconoce la figura del profesor como autoridad y su presunción de veracidad. Esto supone que, ante un conflicto, priman los hechos constatados por el profesor, el cual goza de asistencia jurídica proporcionada por la Administración, así como de cobertura por responsabilidad civil. Destacamos de este resumen al Principado de Asturias por introducir dos principios novedosos: el de inmediación, que permite un mejor conocimiento del problema y es garantía de acierto, y el de celeridad en la reacción, que potencia la eficacia para 


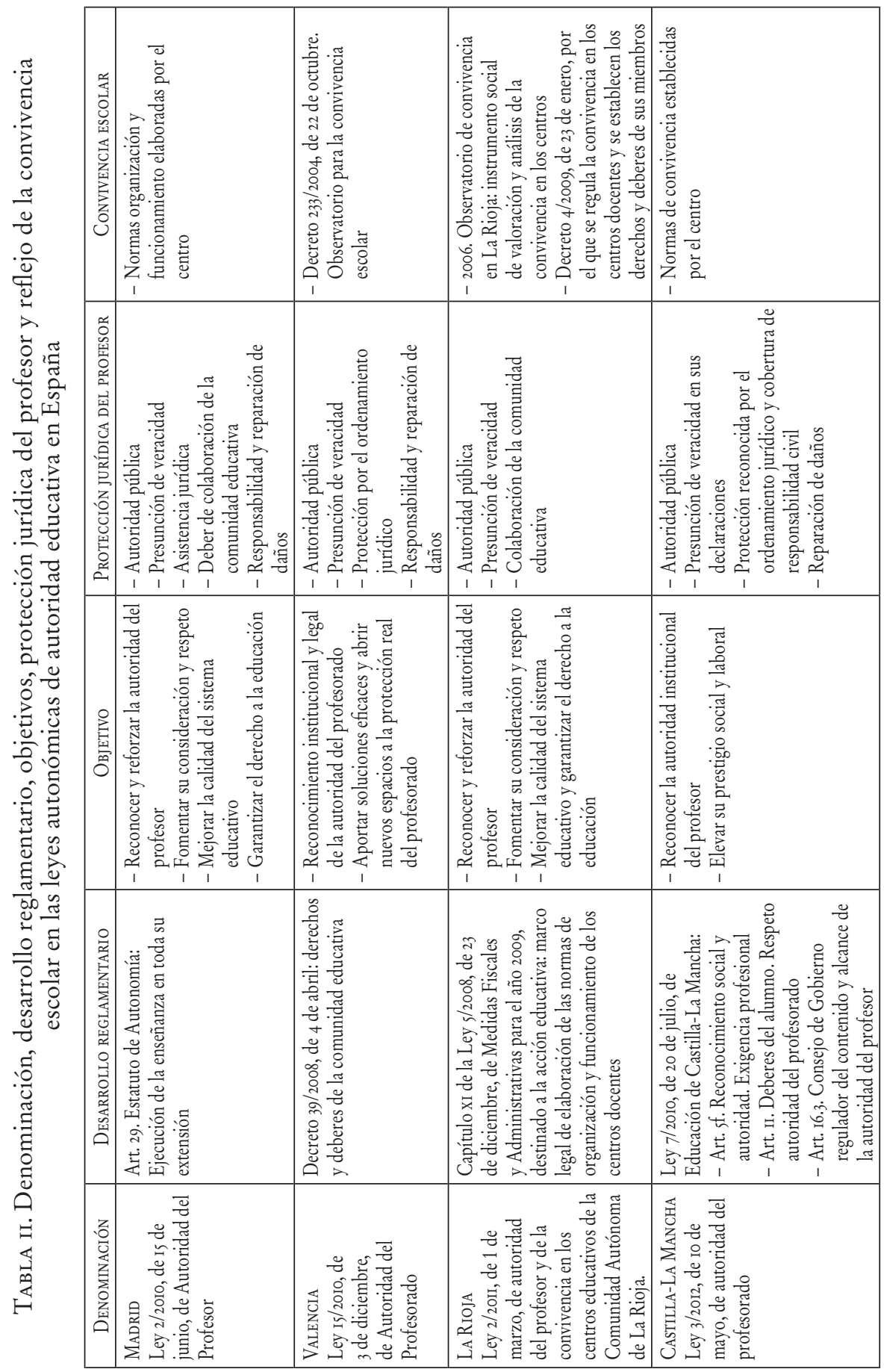


CREANDO PODER: LA EVOLUCIÓN DE LA AUTORIDAD DOCENTE EN ESPAÑA

\begin{tabular}{|c|c|c|c|c|c|}
\hline & 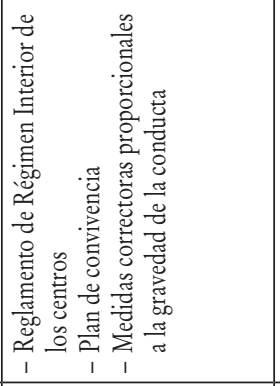 & 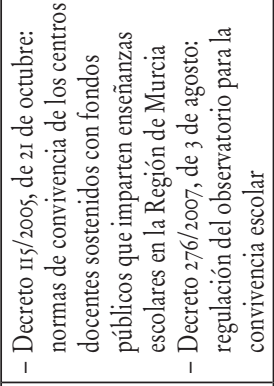 & 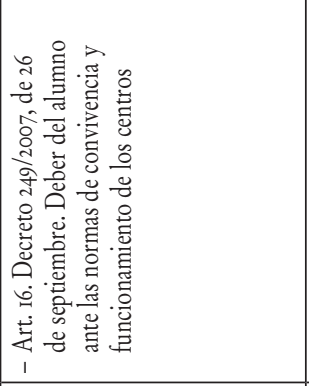 & 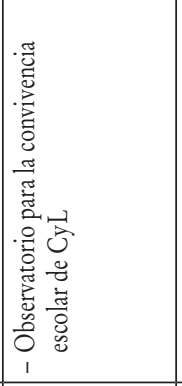 & \\
\hline & 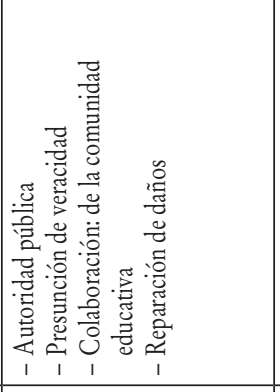 & 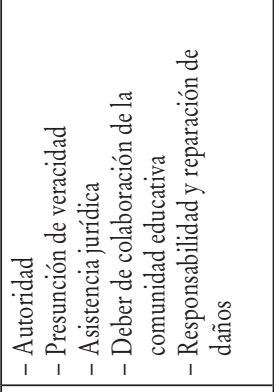 & 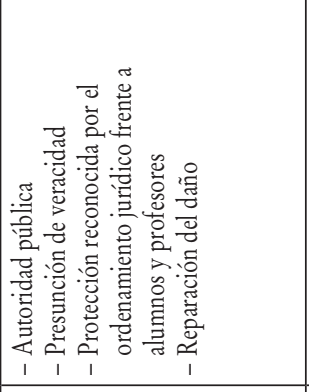 & 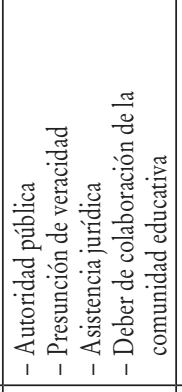 & \\
\hline & 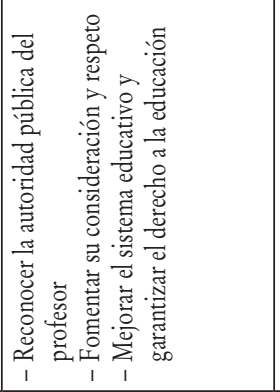 & 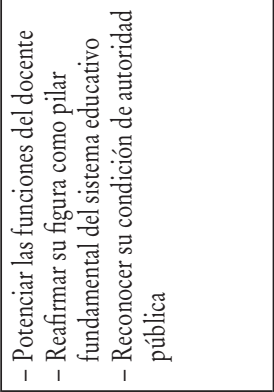 & 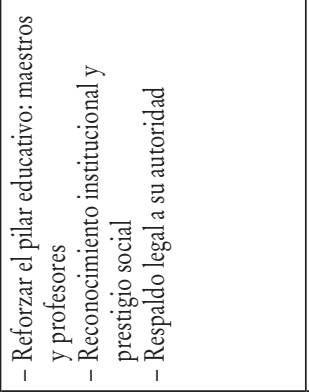 & 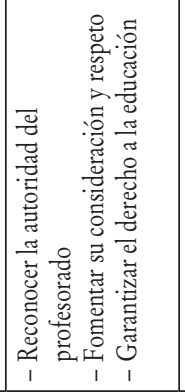 & 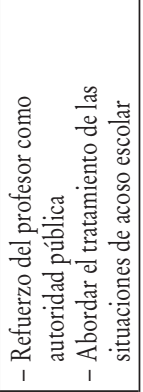 \\
\hline & 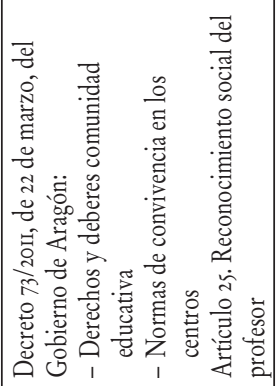 & 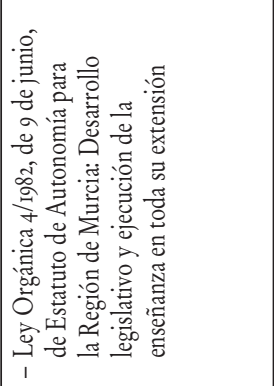 & 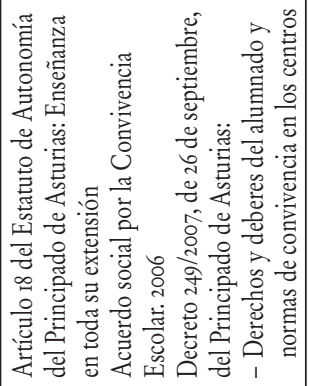 & 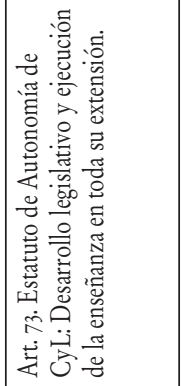 & \\
\hline & 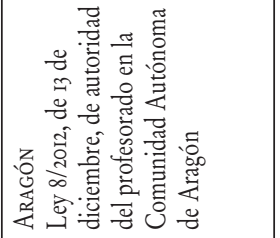 & 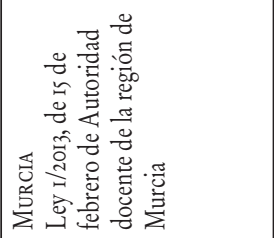 & 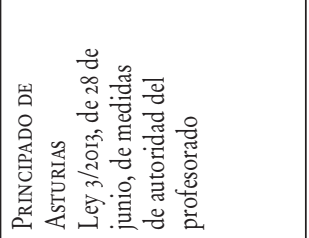 & 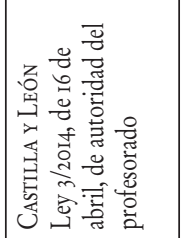 & 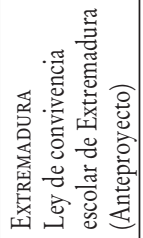 \\
\hline
\end{tabular}


alcanzar los fines de la sanción. En este caso tan particular y diferente del resto, la figura del profesor como agente que puede imponer medidas disciplinarias a los alumnos se sustenta bajo la premisa de que es él, y no el director, el que va a intervenir con inmediatez la conducta de un estudiante que esté impidiendo o dificultando la función docente y alterando la convivencia en clase.

\section{El futuro esperado: de estos barros aquellos lodos}

En la actualidad, el hecho educativo se caracteriza por el incremento de su complejidad. La realidad muestra un nuevo escenario social determinado por la redefinición del papel de la familia, hecho que va a repercutir directamente en la función tradicional de la escuela y en la propia figura del profesorado. Además, la evolución del contexto social ha propiciado un cambio del sentido propio de la institución escolar y lo que se espera de ella. Tal y como manifestaba Martin Cole, en el profesor ha recaído todo el peso de la culpa; la crisis de legitimidad del aula ha desembocado en una pérdida de autoridad del docente, ya que, para muchos alumnos, el objetivo del proceso educativo es la obtención de un título, y es por ello que "para los alumnos que piensan así, la constatación de que las calificaciones no influyen en absoluto en la obtención de un trabajo supone tanto como privar de objeto a la escuela: los profesores, sus conocimientos, sus destrezas pedagógicas, se devalúan» ${ }^{46}$. Parece que el destino laboral de los alumnos ya no está, como antes, en las manos del profesor, quedando socialmente desautorizado como forma de controlar el conflicto escolar.

Es por eso que, desde esta perspectiva, muchos destacan el detrimento de autoridad tanto de los padres como de los propios docentes como causas de la pérdida del rumbo escolar, y señalan que esta situación desvela la existencia de un déficit democrático en el funcionamiento de las escuelas, aspecto que se manifiesta a través de un aumento de brotes de violencia y una preocupación por los problemas de convivencia educativa ${ }^{4}$. Así pues, la convivencia y la disciplina en los centros escolares están siendo objeto de una preocupación actual $4^{8}$ no solo en la sociedad española, sino en otros países. Muestra de ello queda reflejada en la articulación de medidas nacionales e internacionales que vienen a trabajar y a arrojar luz en torno a esta temática. Tal es el caso de la creación, en el 98, del Observatorio Europeo de Violencia Escolar, actual Observatorio Internacional sobre la Violencia Escolar, iniciativa que durante años ha trabajado en la elaboración de estudios en torno a los ámbitos de delincuencia juvenil, acoso escolar o el clima global.

España se suma al objetivo de mejora de la educación planteado desde Europa y, en el curso 20I5/20I6, aprueba el Plan Estratégico de Convivencia Escolar,

${ }^{46}$ Cole, Martin: «La enseñanza hasta el año 2000. La conciencia de los profesores en épocas de crisis», Revista de Educación, 283 (1987), p. 166.

47 García, Francisco: «Formación inicial del profesorado y de los psicopedagogos en educación de la convivencia», Revista Educar, 43 (2009), pp. 43-6o.

${ }_{48}$ EgIDo, Inmaculada: «La autoridad del profesor», Revista Crítica, año 6I, 97I (20II), pp. 71-75. 
impulsado por el Ministerio de Educación, Cultura y Deporte. Con ello, se pretende conseguir que los centros educativos sean espacios seguros, libres de violencia, inclusivos y favorecedores del éxito para todos los individuos. Toma especial relevancia en esta iniciativa la formación del profesorado y la reivindicación de su valor profesional, ya que ello podrá revalorizar su estatus y ensalzar su posición como pieza clave dentro del entramado educativo.

Hemos visto cómo esa preocupación por mantener el orden educativo se manifiesta a través de una fuerte reivindicación de la autoridad del docente, que no va a ser el único eje de articulación de medidas paliativas de violencia escolar, pero sí una de las piezas clave. Y es que, desde diferentes estamentos de la sociedad y desde el propio contexto educativo, son muchas las voces que alertan sobre la necesidad de hacer frente a los llamados alumnos «objetores escolares» ${ }^{49}$, cuyo comportamiento se caracteriza por boicotear continuamente las clases con el fin de desautorizar la figura del profesor. Aunque es cierto que los problemas de disciplina escolar no afectan a todos los sistemas educativos en la misma medida, el ambiente en las aulas perturba los resultados de los estudiantes y puede llegar a ser un desafío para los docentes que, en muchos casos, emplean demasiado tiempo en mantener el orden en el aula.

Es por ello que el debate en torno a la autoridad académica vuelve a tomar fuerza en los últimos años en España, recordándonos que se trata de un «Guadiana» educativo, un tema recurrente que aparece y desaparece, que toma más o menos fuerza y que es impulsado, en algunos casos, por corrientes catastrofistas y nostálgicas que reivindican la recuperación de una autoridad que, aparentemente, se ha perdido, apelando a un pasado educativo más fructífero, supuestamente, en este aspecto.

La implementación de un servicio de «defensa» hacia el profesor no es una medida baladí, sino que debe verse como un reflejo de lo que la comunidad educativa está viviendo en estos momentos. Si nos hemos visto en la necesidad de ejecutar una vía de atención a los docentes, víctimas de situaciones de conflictividad y violencia dentro y fuera del aula, obviamente es porque «algo» está pasando.

Por su parte, el refuerzo institucional de docentes y directores ha reavivado la eterna división de opiniones entre sindicatos de profesores y asociaciones de padres y madres de alumnos. Una confrontación de tendencia natural que no debe empañar la realidad y evidencia que muestra, por un lado, la necesidad de mantener la disciplina en las aulas y, por otro, la de articular la confusión que pueda existir entre autoridad y autoritarismo. Y así lo manifiestan algunas voces que advierten del peligro: «[...], la iniciativa parte de una confusión entre autoridad y autoritarismo y, además de ofrecer una imagen distorsionada de la convivencia en los centros, suscita incluso el recuerdo de una escuela basada en el uso del castigo físico» ${ }^{5}$.

49 BARBA, José Juan: «Redefiniendo la autoridad en el aula: posibilidades para una educación democrática», Revista RETOS. Nuevas Tendencias en Educación Física, Deporte y Recreación, Is (2009), pp. 4I-44.

so EgIDO, Inmaculada: «La autoridad del profesor», Revista Crítica, año 6I, 97I (20II), p. 7I. 
Y es que no solo el poder legítimo otorgado históricamente a los profesores ha disminuido. Como sabemos, determinados medios de control utilizados en el proceso de enseñanza-aprendizaje en las escuelas de los últimos tiempos han pasado a ser conductas perseguidas y penadas por las leyes españolas. Los desarrollos reglamentarios trazan un marco de actuación en el que prima la protección de las personas y amparan especialmente a los menores, prohibiendo el uso de técnicas coercitivas que, con anterioridad, formaban parte de la idiosincrasia escolar. Obviamente, este avance es natural, lo marca el propio ritmo social. El restablecimiento de la autoridad del profesor no implica la vuelta al pasado y a la utilización de técnicas abusivas propias de otras sociedades, pero sí la necesidad de encontrar una vía de convivencia en un plano de respeto.

A todo este conglomerado de circunstancias, debemos sumar un aspecto que marca, en la actualidad, las relaciones existentes entre la escuela y la familia. Se aprecia un cambio significativo en las expectativas que los padres depositan sobre el sistema educativo, entendidas estas más en términos de exigencia que de mutua colaboración. La falta de participación con la comunidad académica viene provocada por una sociedad que se organiza desde el sistema productivo, nunca desde el educativo, y esto provoca un desgaste a nivel familiar. Padres y madres derivan responsabilidades hacia el sistema educativo y, en muchos casos, basan las relaciones con sus hijos en la permisividad precisamente para compensar carencias vitales de atención. El último informe publicado por el sindicato AMPE, «El defensor del profesor» que recoge datos del curso 2016/20I $7^{\text {sI }}$, nos muestra cómo se mantiene la puntuación (29\%) de denuncias recibidas respecto a acoso y amenazas de padres a profesores, así como las denuncias de padres a profesores $(19 \%)$, con respecto a otros cursos, aspecto que manifiesta que hay problemas en esa relación primordial como es la de familia y escuela.

Por todo ello, entendemos que se hace explícita la necesidad de propiciar un cambio de paradigma que combine la autoridad familiar y la escolar, lo que implica educar en la responsabilidad. Dicho en otras palabras, entender que la escolaridad no es, exclusivamente, una «obligación», un «trámite» sino una posibilidad, un medio.

\section{A modo de conclusión}

«Cuando en un pueblo sólo sabían leer y escribir el maestro, el cura, el médico, el secretario del ayuntamiento y unos pocos más, la autoridad a ellos reconocida era muy elevada» ${ }^{2}$. Nos referimos a aquellos tiempos en los que el analfabetismo era generalizado y la cultura propia de los maestros, y, sobre todo, su misión de transmitirla, les otorgaba un plus de autoridad con respecto al pueblo.

st El Defensor del Profesor: Informe del defensor del profesor con sus conclusiones 2016-20I7, 2017, en https://eldefensordelprofesor.es/documentos-informes.

${ }_{52}$ TRILla, Jaume: «Sobre la autoridad supuestamente perdida del profesorado», Cuadernos de Pedagogía, 396 (2009), pp. 25-26. 
Sin embargo, en las últimas décadas, el papel tradicional del profesor, respetado por padres y alumnos, transmisor de conocimientos y valorado especialmente por su autoridad cultural, por el hecho de desempeñar la misión otorgada por la sociedad de culturizar a los más jóvenes, se ha ido desfigurando.

Usategui y Del Valle ${ }^{s_{3}}$ destacan varios factores determinantes del desgaste de la autoridad tradicional del profesor. El relativismo cultural y moral, la democratización de la sociedad, que propicia el reemplazo de un estilo educativo basado en el mandato hacia otro sustentado por modelos de relación más participativo, serían algunos de esos condicionantes. Precisamente, la confusión de democracia con igualitarismo, las prácticas de relaciones entre profesor y alumno como si fueran agentes iguales, pueden ser un caldo de cultivo para la proliferación de un desajuste en el rol de los docentes.

Además de estas relaciones sociales más igualitarias, los procesos democráticos introducen una extensión de la educación, aspecto que provoca cambios sustanciales en la relación del docente con su «clientela». El nivel cultural de las familias de los alumnos ha variado y este hecho supone una pérdida de autoridad del profesor que ya no ostenta el papel de sabio y que incluso puede ver cómo se cuestiona su labor e identidad docente desde los más variados estamentos.

Los valores que priman actualmente en la sociedad podrían explicar, en cierta medida, muchos de los comportamientos de los alumnos, así como las dificultades a las que se enfrenta el profesor, derivadas de una sociedad postmoderna, basada en el bienestar individual.

El hecho ha desencadenado la articulación de medidas legales que intentan frenar lo que para algunos parece ser una tendencia peligrosa. Pero ninguna fuerza legislativa va a conseguir transformar la realidad, ya que esta es mucho más compleja. Es por ello que estas disposiciones reglamentarias solo pueden plantearse como un apoyo, un respaldo, un marco de acción, pero nunca como una solución o una imposición.

Es necesario ir más allá. El profesor necesita mucho más que una simple ley para ser reconocido como una figura de autoridad. Quizás el problema no esté en la escuela sino en la sociedad. Nuevamente se apela a la colaboración entre el binomio familia y escuela. Reclamar la autoridad del profesor no debería entenderse como una pérdida de libertad individual del alumno, sino como la necesidad de un aprendizaje de democracia en las aulas.

53 Usategui, Elisa y Del Valle, Ana Irene: «Luces y sombras de la función docente desde la mirada del profesorado», Revista Electrónica Interuniversitaria de Formación del Profesorado, 29 $($ I2, 2) (2009), pp. 19-37. 
